\title{
Giras on-line: Umbanda reconfigurada
}

\author{
Maurício Ferreira Santana ${ }^{1}$
}

\begin{abstract}
Resumo: O momento de crise causado pela pandemia de coronavírus (COVID-19) no início do ano de 2020 implicou um deslocamento da prática religiosa do espaço físico para o espaço virtual. A solução encontrada por pais e mães de santo foi adotar o recurso tecnológico das redes sociais para executarem a prática litúrgica (giras de Umbanda) em formato on-line, através de lives, devido à impossibilidade de abertura dos terreiros à egrégora, parcial ou totalmente. Partindo do pressuposto de que a Umbanda é um processo comunicacional caracterizado pela tríade "entidade/médium/consulente", observa-se, através da análise de vídeos de giras on-line disponibilizados na plataforma YouTube, uma experiência diferenciada na questão da religiosidade, interação e incorporação (com base teórica em Mircea Eliade, Muniz Sodré e Luís Mauro Sá Martino), pois o espaço sagrado, ao mesmo tempo palco litúrgico, fragmentase para também surgir para o espectador, no espaço virtual e acaba por reconfigurar aspectos comunicacionais e basilares da religião.
\end{abstract}

Palavras-chave: Umbanda; reconfiguração religiosa; espaço sagrado; YouTube.

\section{On-line giras: Umbanda reconfigured}

\begin{abstract}
The moment of crisis caused by the coronavirus pandemic (COVID-19) at the beginning of 2020 implied a shift in religious practices from physical to virtual spaces. The solution found by "pais e mães de santo" was to adopt the technological resources of social networks to perform liturgical practices ("giras de Umbanda") in an online format, through lives, due to the impossibility of opening the "terreiros" to the egregore, partially or totally. Based on the assumption that Umbanda is a communicational process characterized by the "entity / medium / consultant" triad, it is possible to observe, through the analysis of online "giras" videos available on YouTube, a different experience in the matter of religiosity, interaction and incorporation (with theoretical basis in Mircea Eliade, Muniz Sodré and Luís Mauro Sá Martino). The sacred space, at the same time liturgical stage, has been fragmented in order to be performed on virtual spaces, reconfiguring the communicational and basic aspects of religion.
\end{abstract}

Keywords: Umbanda; religious reconfiguration; sacred space; YouTube.

\footnotetext{
Doutorando em Comunicação pela Universidade Tuiuti do Paraná; mestre em Teoria Literária pela Uniandrade - PR; especialista em Gestão da Informação pela FESP-PR (2002) e em Comunicação, Cultura e Arte pela PUC-PR; graduado em Biblioteconomia pela Universidade Federal do Paraná (1997). E-mail: jose_sandino@yahoo.com.br .
} 


\section{Introduçáo}

Existem diferenças entre as religióes mediúnicas, em especial, as de matriz africana, e as religiôes predominantes no Brasil, como catolicismo e protestantismo (igrejas evangélicas), no que diz respeito à questão da experiência religiosa fora do chamado espaço sagrado (o templo, o espaço físico de culto). Enquanto que uma missa católica ou um culto evangélico têm ampla divulgação em diferentes mídias (comumente na televisão e em canais de streaming), possibilitando a manifestação da religiosidade, ou seja, facultando a experiência (MIKLOS, 2010, p. 40; MARTINO, 2016, p. 152), nas religióes de matriz africana, o tipo de experiência fora do espaço sagrado (o terreiro) parecia até então irrealizável, visto a existência de particularidades que exigiam a prática em locais físicos, protegidos espiritualmente, ou seja, nos terreiros, os quais também são espaço território-corpo de resistência identitária: “[n] a Umbanda, os processos simbólicos de iniciação também estão ligados a uma definição de identidade. A frequência a um terreiro [...] também se refere ao estabelecimento de quem se é." (MARTINO, 2016, p. 140, ênfase acrescentada).

A inquietação que instigou a elaboração deste artigo foi justamente uma interrupção da experiência religiosa do autor ${ }^{2}$ e da impossibilidade de ter contato físico com o terreiro (um para um e todos para todos), causada pela pandemia de coronavírus, no início do ano de 2020. Sendo assim, surge o problema: Como manifestar a religiosidade se há o impedimento de comparecer ao local de culto? De que maneira a egrégora umbandista pode executar sua liturgia afastada do espaço sagrado, fragmentada e desconectada da corrente energética do terreiro?

Neste artigo, é abordada a questáo da experiência religiosa - presumida como reconfigurada, dadas as justificativas adiante - na religião de Umbanda, procurando lançar questôes sobre novas abordagens na questão da experiência umbandista, utilizando-se, como recorte temporal, a pandemia de coronavírus (COVID-19), que atingiu o território brasileiro em meados de março de 2020, obrigando o fechamento dos terreiros. A problemática tratada é a ausência presencial no espaço sagrado para a prática religiosa e a busca de alternativas - o espaço virtual, profano - que é um paliativo à questão da necessidade de se vivenciar a experiência. No entanto, é caracterizada como uma experiência desterritorializada, pois, longe do espaço sagrado, náo se pode reunir os três principais elementos da hierofania umbandista, denominados, nesta investigação, como uma "tríade"3: entidade/médium/consulente.

O espaço sagrado, segundo Mircea Eliade (2019), “implica uma hierofania, uma irrupçáo do sagrado que tem como resultado destacar um território do meio cósmico que o envolve e o torna qualitativamente diferente". (ELIADE, 2019, p. 30). A hierofania aqui citada é emprestada também de Eliade como "algo de sagrado [que] se nos revela [e] manifestaçóes das realidades sagradas" (Ibid., p. 17), que também tem como intenção gerar o que, nas religióes

\footnotetext{
2 O autor participou como integrante da egrégora do Terreiro de Umbanda Vó Benedita (atualmente Tia Serafina), além de ter efetuado observação participante no Terreiro de Umbanda Caboclo Girassol, no período 2017-2020. Ambos os terreiros estão localizados na cidade de Curitiba, Paraná.

3 Florence Dravet utiliza a expressão “troca triádica” (DRAVET, 2016, p. 295).
} 
afro, se denomina "axé", energia que envolve tanto a ancestralidade, quanto o "sentir" os orixás. Muniz Sodré (2006) entende o axé como uma arkhé similar àquela concebida pelos pré-socráticos da Escola de Mileto, sobretudo em Anaximandro, uma substância primária, o "[...] infinito, eterno e imperecível que 'abarca todos os mundos'[...]". (RUSSEL, 2015, p. 52). Na arkhé africana, "[...] o corpo se concebe como um microcosmo do espaço amplo (o cosmo, a região, a aldeia, a casa)”. (SODRÉ, 2006, p. 211). O axé, portanto, é parte inerente de um fluxo comunicacional de mediaçáo entre o Aiyê (o plano terreno, na língua iorubá) e o Orun (o céu ou o mundo espiritual).

Como objetos de estudo, optou-se pela escolha de dois canais do YouTube pioneiros na execução de giras online: o primeiro é o canal Adérito Simóes, transmitido pelo pai de santo homônimo, e o segundo, o canal Umband'Boa, transmitido pelo pai de santo Márcio Kaim ${ }^{4}$. Os critérios adotados para a escolha desses canais, além do pioneirismo, foram o número de inscritos e a quantidade de visualizaçóes. A opção pelo YouTube se deu pela qualidade dos streamings, bem como pela facilidade de organização dos vídeos em playlist pessoal, para análise detalhada. Algumas dessas giras também foram transmitidas pelo Facebook.

\section{Terreiro, território, corpo}

Se, até recentemente, só se "tocavam" as giras dentro dos terreiros, com a presença de toda a egrégora (pai/mãe de santo, médiuns, cambones ${ }^{5}$, ogãs ${ }^{6}$ ) e os consulentes - e, aqui, entenda-se qualquer espaço sagrado onde exista pelo menos um pai/máe de santo e um mínimo de médiuns, podendo ser desde um barracão até uma garagem ${ }^{7}-$, o que fazer quando não se pode abri-los devido a um momento de crise? Não se pode dar passagem às entidades (incorporação), não se podem efetuar os descarregos (limpeza espiritual)? Conforme Martino (2016):

[...] em momentos de crise, quando a pessoa se vê diante de situaçóes inesperadas, geralmente começam os questionamentos a respeito de quem se é, do que se faz, de qual é seu futuro - e como entender o passado. Nesses momentos, a pessoa é levada a pensar a respeito de si mesma: a certeza tranquila a respeito de quem sou é colocada em jogo, e sou obrigado a fazer uma quebra entre quem eu era, ou achava que era, e quem eu sou diante dessa nova situaçáo [...]. A partir dessa crise,

\footnotetext{
4 O canal Adérito Simões possui cerca de 320 mil inscritos; o canal Umband’Boa, 180 mil. Levantamento realizado em 11 de maio de 2021.

5 Encarregado de auxiliar os médiuns incorporados, bem como de fazer anotações, cuidar de detalhes da organização do terreiro, dar explicações aos consulentes (BARBOSA JÚNIOR, 2014, p. 215).

6 O ogã relaciona-se à curimba (instrumentos de percussão, como atabaques), dedicando-se ao toque e ao canto (BARBOSA JÚNIOR, 2014, p. 215).

7 Evidentemente, um terreiro possui complexidade de elementos. Em resumo, pontos vibracionais (pontos energéticos e de segurança), assentamento (elementos que formam uma matriz energética da entidade que "chefia" o terreiro), firmeza (acendimento de velas para os Orixás, guias e protetores espirituais, para manter o vínculo energético), tronqueira (local destinado ao Exu protetor do terreiro, geralmente localizada na entrada), cruzeiro das almas (local específico para acendimento de velas aos Pretos Velhos, o orixá Obaluaê e todas as almas), congá (altar, semelhante ao da igreja católica, onde ficam dispostas as imagens dos orixás e demais entidades), etc. Para detalhes específicos, ver Barbosa Júnior (2014, p 216-219).
} 
dessa "separação" de quem se era, novos elementos vêm se adicionar à identidade, enquanto outros desaparecem. (MARTINO, 2016, p. 139).

Considera-se, como espaço sagrado na Umbanda, o terreiro (no Candomblé, também são sinônimos roça e egbé), o centro e a realidade do mundo umbandista, que lhe confere identidade:

O homem deseja situar-se num 'centro', lá onde existe a possibilidade de comunicação com os deuses [...]. O corpo humano, assimilado ritualmente ao Cosmos [...] é também assimilado a uma casa [..., o templo ou a casa, por sua vez, são considerados como um corpo humano. (ELIADE, 2019, p. 141-42).

É no terreiro, espaço sagrado, que se desenvolve a liturgia da gira, incluindo a incorporaçáo (onde o corpo se assimila ao Cosmos): “[h]á, portanto, um espaço sagrado, e por consequência 'forte', significativo, e há outros espaços não-sagrados, e por consequência sem estrutura nem consistência, em suma, amorfos" (ELIADE, 2019, p. 25). O espaço sagrado, portanto, no caso da gira on-line, continua o sendo, porém agora mediatizado, ou seja, considerando-se a religiáo de Umbanda como um processo social, esta sofre, em alguma medida, influência das mídias. Essa influência pode ocorrer em um processo de alta mediação - uso intenso das mídias, como, por exemplo, o recurso do televangelismo - ou baixa mediação - um uso pontual ou até emergencial, como é o caso do recurso utilizado para transmitir os ritos, em um momento de pandemia (MARTINO, 2016, p. 44-45). Similarmente, pode-se considerar também um processo de mediatização direta, visto que "[...] uma atividade antes não mediada adquire uma forma mediada - isto é, a atividade passa a ser realizada a partir da interação com um meio [de comunicação]”. (HJARVARD, 2014, p. 41).

Uma primeira impressão desse processo mídia-religião está em depoimento do pai de santo e youtuber Adérito Simóes, em sua primeira gira on-line, transmitida por streaming: “[e] sta casa, agora, em todo o momento em que for necessário, estará aberta on-line ou fisicamente para irradiar até vocês. Que a força de Umbanda seja sempre presente junto a todos vocês [...]". (GIRA ON-LINE, 2020a, 23min57s).

É bastante relevante o fato de que a incorporação, aqui considerada como o estado pleno religioso, a própria hierofania, ocorreu em algumas das giras online que foram objeto de investigação e em outras não. Segundo alguns pais e mães de santo, bem como filhos de fé, os quais manifestaram suas opiniôes nos comentários das lives, a incorporação não deve ocorrer fora dos terreiros, ou seja, só pode acontecer dentro do espaço sagrado, pois, para eles, incorporar em casa não é um ato seguro. Em sua primeira gira on-line, o pai de santo e youtuber Adérito Simóes (cujo canal leva seu nome), do Templo de Umbanda Sete Montanhas, localizado no Município de Praia Grande, São Paulo, frisou: “[...] isso é novo [a realização de uma gira ao vivo], não vai ter incorporação, obviamente, mas a força vai acontecer” (GIRA..., 2020a, $8 \min 25 \mathrm{~s})$. 
Para os umbandistas, o fato de incorporar fora do terreiro implica diversos perigos do ponto de vista espiritual, visto que não há a proteção energética do espaço sagrado. Adérito Simóes reforça essa recomendação:

[...] eu não tenho como amparar vocês nas suas casas, porém eu não estou na sua casa para saber o que está acontecendo, certo? O que eu digo é: se possível, não incorpore, mas eu não tenho controle sobre nada, eu apenas faço aquilo que deve ser feito. Eu digo: não incorpore [...] meus filhos de santo [também] devem segurar [a incorporação]. (GIRA..., 2020a, 24min50s).

Já o pai de santo Márcio Kain, do Terreiro de Umbanda Francisco de Assis (TUFRA) localizado no Município de Sorocaba, São Paulo - e youtuber do canal Umband’boa, utilizou as incorporaçóes durante sua primeira gira ao vivo, bem como recomendou a incorporação em casa somente para médiuns ${ }^{8}$, com ressalvas. Segundo as palavras do mesmo:

Se você está bem, só está se sentindo carregado, mas mentalmente você está com a mente firme e equilibrada, pode incorporar sem problema nenhum, meu filho [...]. Se você sentir a vibração, ótimo, deixe a entidade na incorporação limpar você. Isso para aqueles que são médiuns. Agora, se você está num momento onde você tem medo, angústia, ansiedade, tristeza, desequilíbrio de qualquer natureza ou está passando por um problema grave eu peço a você: não incorpore. (LIVE..., 2020a, 1min04s).

Nota-se que, tanto para Adérito Simóes, quanto para Márcio Kaim, a preocupação com a incorporação está diretamente relacionada ao estado mental e espiritual do espectador, seja ele médium do terreiro que transmite a gira em vídeo, seja médium de outro terreiro. Deve-se entender, por isso, que, mesmo no espaço sagrado, o médium de incorporação deve estar em estado físico e espiritual ideal para a prática religiosa, seguindo diversos preceitos, entre os quais os mais comuns são a abstinência de carne, bebidas alcoólicas e relaçóes sexuais em períodos estabelecidos pelo pai/mãe de santo: "[E]sses procedimentos visam a desobstruir os pontos de captação de energias e afinizar a vibração do médium em seu padrão pessoal.” (ESPÍRITOS..., 2004, p. 82). Portanto, deve-se complexificar o fenômeno da incorporaçáo, estado de hierofania umbandista, como um componente pertencente à liturgia, ligado ao fundamento religioso e como um processo comunicacional da esfera espiritual para a esfera terrena.

\section{Entidade, médium e consulente: uma tríade}

O fenômeno dos youtubers dedicados a propagar a religião de umbanda não é novo. Aspectos de processos comunicacionais como a mediatização são perfeitamente aceitáveis através do formato dos canais, quando estes são dedicados a propagar a ideologia da religião, tirar dúvidas dos espectadores sobre práticas e fundamentos, promover e divulgar cursos

\footnotetext{
8 A princípio, toda e qualquer incorporação só é possível a quem tem a denominada mediunidade. No entanto, para as religiões mediúnicas, existem médiuns não só de incorporação, mas também de vidência, de cura etc. (AZEVEDO, 2008, p. 27-28).
} 
on-line, entre outros temas: "[A] mídia religiosa no contexto da Umbanda é operada por diferentes praticantes, que interpretam seus rituais e dáo sentido a eles em contato com outros fiéis, mediada por dispositivos tecnológicos." (TEIXEIRA FILHO; AZEVEDO JÚNIOR, 2019 , p. 228). Isso se caracteriza como um processo mediatizado direto, segundo Stig Hjarvard (2014). Voltando a Martino (2016), a mediatização da religião

[...] pode ser entendida como a articulação de características dos meios de comunicaçáo, com sua linguagem, seus códigos, seus limites e possibilidades de construção de mensagens nas práticas, formaçóes e instituiçóes religiosas. A midiatização não é uma relação passageira ou ocasional, mas um processo no qual tanto a mídia quanto a religião se articulam em práticas e ações comuns. (MARTINO, 2016, p. 39).

Por outro lado, não se deve afirmar que a Umbanda mediatizada sofre (ou sofrerá) mudanças determinadas pelas tecnologias digitais como uma forma cultural, visto que eventuais mudanças e reconfigurações na religião não se dão meramente por determinismo tecnológico (WILLIAMS, 2016, p. 26-27; MARQUIONI, 2018, p, 56). Deve-se entender a tecnologia do streaming e das plataformas de vídeos como recursos utilizados que levam "a bandeira de Oxalâ" as diferentes umbandas - a um público desterritorializado. Segundo Pierre Lévy, "[q]uando uma pessoa, uma coletividade [...] se virtualizam, eles se tornam 'não-presentes', se desterritorializam" (LÉVY, 2011, p. 21). Esse público-alvo se encontra fora do espaço sagrado, atualmente, como resposta a um momento de crise que impede a união da egrégora. Teixeira Filho e Azevedo Júnior vão além da questão determinista, incluindo também os meios e as mediaçôes:

As alteraçóes nas religióes ultrapassam o uso da televisão, do rádio e da internet, embora a competência técnica tenha sustentado parte das mudanças na camada discursiva e do fazer religioso. Portanto, ao pensar as transformaçóes da $\mathrm{m}[\mathrm{e}]$ diatização da religião, a concentraçâo ocorre no sentido de interpretar como a lógica dos meios e das mediaçóes comunicativas da cultura direciona a prática religiosa, e não apenas como a mídia e as novas tecnologias são utilizadas por organizaçôes ou praticantes. (TEIXEIRA FILHO; AZEVEDO JÚNIOR, 2019, p. 213).

Por outro lado, canais de umbanda não propunham, até recentemente, executar o processo litúrgico (gira) exclusivo do espaço sagrado (terreiro) sem a presença de toda a egrégora. Via streaming, tem-se, então, outro tipo de experiência não corporal/presencial para o espectador, isto é, a experiência religiosa emulada on-line ${ }^{9}$, cuja causa pode ser detectada pelo momento de exceção no País, no ano de 2020, ou seja, a pandemia de coronavírus. Nessa "encruzilhada" de experiências, é necessário costurar os elementos, agregando também, como importante na experiência do espaço sagrado, a questão do atendimento individual e da experiência corporal. Similarmente, de acordo com Miller e Slater (2000), poder-se-ia considerar a questão da confissão católica, onde o sacerdote náo vê o confidente e vice-versa, porém ambos ocupam o mesmo espaço presencialmente, e também a comunhão, o recebimento da hóstia sagrada

9 O conceito de prática religiosa emulada está sendo desenvolvido na tese de doutoramento do autor. 
(MILLER; SLATER 2000, p. 185), implicando reconfiguraçóes dos sacramentos (SPADARO, 2013; SOUZA, 2013). Para Sodré (2002), os cultos de matriz africana (como Candomblé, Umbanda, entre outros) têm uma indissociabilidade do fator corporal e do contato físico:

$\mathrm{Na}$ cosmovisão desses cultos, de modo análogo à atitude hindu, colocam-se em primeiro plano o reconhecimento do aqui e agora da existência, as relaçóes interpessoais concretas, a experiência simbólica do mundo, o poder afetivo das palavras e ações, a potência de realização das coisas e a alegria frente ao real [...da] experiência do sagrado em sua radicalidade. Decorre daí a grande importância outorgada ao corpo. (SODRÉ, 2006, p. 210).

Piza e Silva (2019) também apontam para a questão do corpo como elemento indissociável no rito, ao mesmo tempo em que apontam o youtuber umbandista como objeto para digressóes sobre mediatização - mesmo que, nesse caso, o exemplo proposto pelos autores tenha sido para contextualizar o formato do posicionamento de marca e do consumo, e náo da experiência religiosa propriamente dita.

Religiôes mediúnicas, dentre elas mais especificamente a Umbanda, nas quais a relação de culto se constitui essencialmente em mídia primária, da comunicação corpo a corpo, não possuem ritual no qual ocorram preleçôes, uma vez que a mensagem ao fiel é personalizada, associada, portanto, a um contexto pessoa a pessoa. Tal cenário passa a se alterar na medida em que os processos midiáticos baseados em mídia terciária se desenvolvem no sentido de uma comunicação em rede, muito presente na dinâmica da internet. Nesta composiçáo, plataformas como Youtube - de circulação de conteúdos culturais, informativos e científicos - streaming de vídeos - passam, como em outros setores da sociedade, a propor contextos comunicacionais associados à lógica multidirecional (diversos emissores e receptores, atuando associativamente em rede). Nesta perspectiva, vemos emergir um novo fenômeno, que denominamos Youtubers Umbandistas. (PIZA; SILVA, 2019, p. 7).

Buscando-se uma problematização da questão da gira "presencial” reconfigurada na gira on-line, caracterizada como o espaço sagrado em contraposição ao espaço virtual, faz-se necessário mencionar um aspecto que é o próprio desdobramento da tríade como elemento de mediação e comunicação: o principal fundamento da Umbanda, "a manifestação do espírito para a caridade". Tal fundamento foi proferido pelo espírito Caboclo das Sete Encruzilhadas, através do médium Zélio Fernandino de Moraes, em 15 de novembro de 1908 (AZEVEDO, 2008, p. 9; REIS, 2011, p. 46; JURUÁ, 2013, p. 19; BARBOSA JÚNIOR, 2014, p. 22; OMOLUBÁ, 2014, p. 13), data esta considerada como o marco de fundação da religião. Manifestar o espírito para a prática da caridade significa estabelecer comunicação entre o "mundo espiritual" e o "mundo terreno". O espírito se manifesta através do médium. Como o próprio termo sugere, é ele que será o mediador (e também o decodificador) das informaçóes transmitidas pela entidade espiritual ao consulente ${ }^{10}$.

\footnotetext{
10 Optou-se pela expressão "consulente" para indicar aquele que se consulta com as entidades espirituais, que é parte da egrégora não presente na corrente mediúnica. Termo similar também utilizado é "assistência”, o que pode gerar confusão com assistentes de terreiro
} 
Para que se possa compreender melhor o processo, define-se a tríade da seguinte maneira: um (A) espírito (ou entidade, no jargão umbandista), para se manifestar, necessita estar incorporado em um (B) ser humano (o próprio médium, chamado de aparelho ou cavalo também no jargão religioso) para que possa, através dele, efetuar a prática da caridade, ou seja, irradiar a sua energia (axé) com várias finalidades, sejam passes energéticos, limpeza espiritual com a utilização de elementos como fumo e ervas ou simplesmente a transmissão de palavras de esperança, fé e aconselhamento ao (C) consulente. Portanto, para que o fundamento "manifestação do espírito para a caridade" tenha efeito, é necessária a indissociabilidade dos elementos $(\mathrm{A})+(\mathrm{B})+(\mathrm{C})$ dentro do espaço ideal para essa comunicação, ou seja, presencialmente, dentro do terreiro.

\section{-A gira on-line como ruptura}

A gira online é uma forma desterritorializada parcialmente de proporcionar uma experiência religiosa aos umbandistas confinados em suas casas, devido à pandemia. Mas ela é indesterritorializada para quem está no espaço sagrado, executando e transmitindo ao vivo a liturgia. Isso é feito por causa da proibição de práticas religiosas com aglomerações de público, durante o recorte temporal observado. Logo, enfatiza-se o caráter emulado dessa prática, visto que a liturgia náo está completa de acordo com o fundamento exposto anteriormente.

\section{Figura 1 - Frame de uma gira on-line de Adérito Simóes}

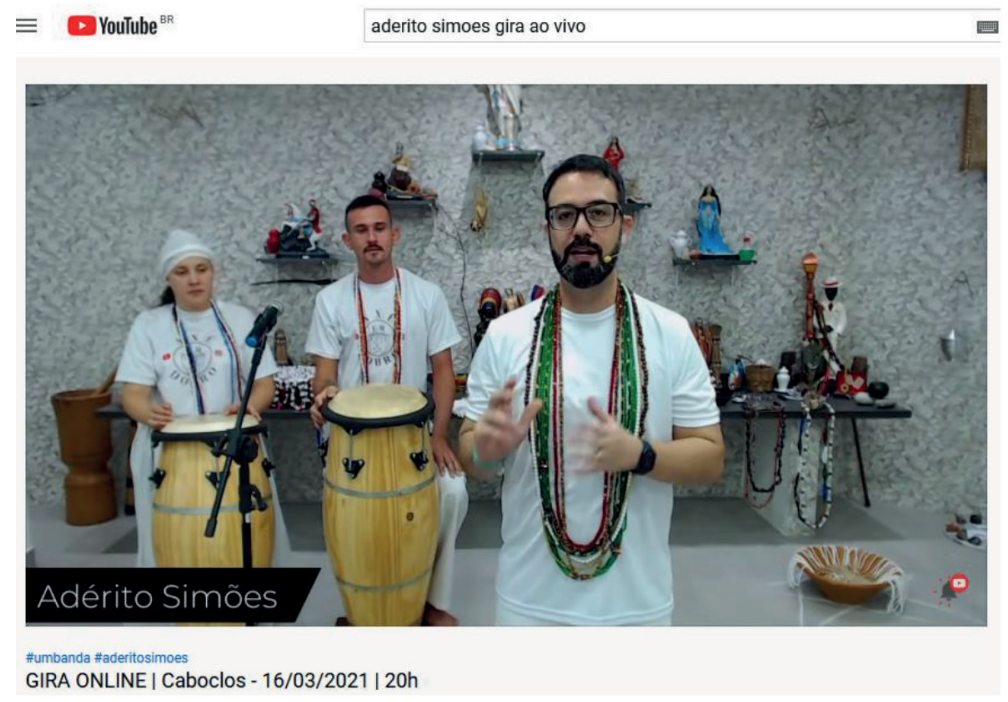

Fonte: YouTube. Disponível em: https://www.youtube.com/watch?v=DTwzOgixOgI. Acesso em: 10 maio de 2021.

(cambones). Julgou-se mais adequado, portanto, a substituição por "consulência". Essa expressão também é respaldada por Florence Dravet (2016). 


\section{Figura 2 - Frame de uma gira on-line de Márcio Kain}

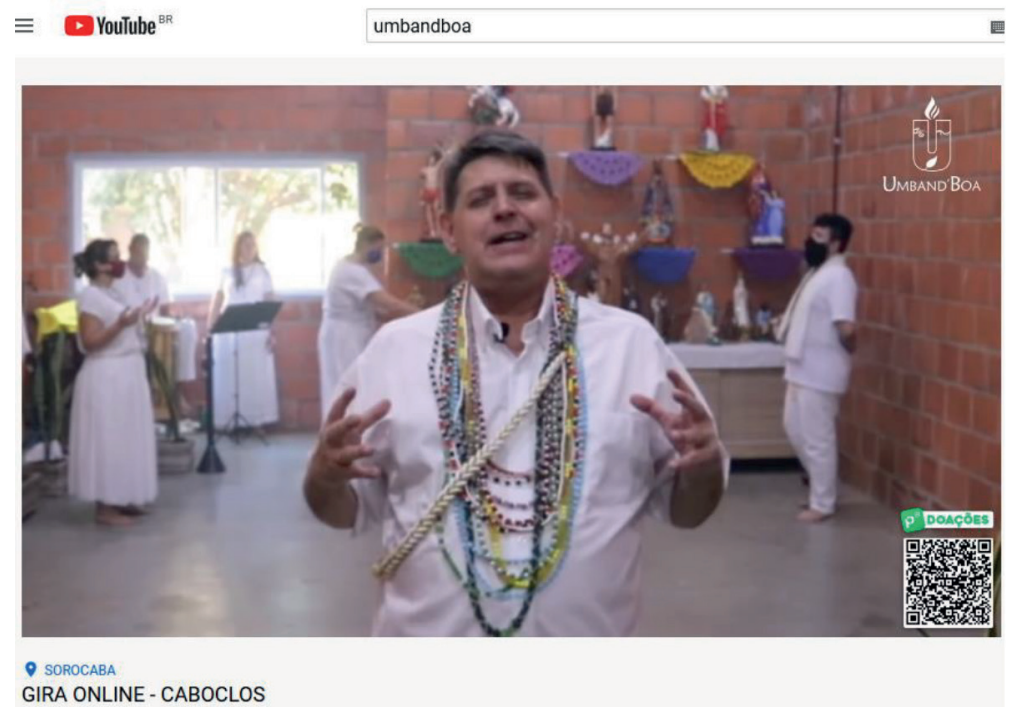

Fonte: YouTube. Disponível em: https://www.youtube.com/watch?v=P92dWB9UMIY. Acesso em: 10 maio de 2021.

O caráter de emulação na gira on-line também é observado por Adérito Simões, em sua primeira gira nesse formato, ao afirmar: "[...] que eu fiz? Eu firmei todo o terreiro, coloquei tudo pra frente, não tenho a menor ideia do que eu vou fazer. Pra mim vai ter uma gira.” (GIRA...., 2020a, 4min24s). Adérito Simóes também evoca a consciência de que sua egrégora está desterritorializada, ratificando novamente o aspecto emulado:

Saúdo [...] toda a minha comunidade de santo [...], todos os filhos de Umbanda e toda a minha egrégora que aqui [dirigindo-se aos espectadores] está nos acompanhando hoje, aos trancos e barrancos, [...] sem conseguir transmitir tudo o que é possível, fazendo o que dá, não temos a menor ideia de como está saindo pras pessoas [...]. (GIRA..., 2020b, 10min43s).

A experiência religiosa no espaço sagrado, corporal e presencial, acima de tudo (como já citado em Sodré e Eliade), inclui o atendimento espiritual "um para um”, ou seja: para cada consulente, uma entidade para auxílio. Na liturgia resumida por Ademir Barbosa Júnior (2014): "[V] ariaçôes à parte, [as giras] costumam ter mais ou menos a mesma estrutura: firmeza para Exu; abertura; defumação; preces e saudaçôes; atendimentos e/ou consultas e trabalhos propriamente ditos; encerramento." (BARBOSA JÚNIOR, 2014, p. 220).

Vale mencionar que certas vertentes de Umbanda, além do atendimento individual, também promovem passes energéticos coletivos, mas, nesse caso, ainda demandam a presença corporal, pois os médiuns incorporados lançam mão de recursos como fumo, velas, ervas, água etc., aplicados diretamente nos consulentes. De qualquer forma, tanto Adérito Simóes como Márcio Kain buscaram adaptar essa ritualística a seus espectadores, nas giras observadas, como uma prática que caracteriza emulação. Adérito Simôes ilustra o aspecto de emulação da gira on-line, dirigindo-se à audiência da seguinte forma: 
Salve a tudo e a todos. Dou por aberta aqui a nossa gira, para o nosso trabalho, para edificação da nossa Umbanda e levando o axé para todos que estão necessitados em casa. Coloquem as mãos, já que eu não posso dar um passe, já que eu não consigo dar uma consulta, coloquem vossas mãos estendidas à frente [...], fique [dirigindo-se ao espectador] agora propício, aberto, para receber as forças do plano espiritual. (GIRA..., 2020a, 20min38s, ênfase acrescentada).

Presente no espaço sagrado indesterritorializado, Márcio Kaim (e parte da egrégora composta por alguns médiuns) procurou também emular, via streaming, a energia do seu terreiro (axé) para o espaço virtual dos espectadores desterritorializados:

Toda a equipe espiritual está aqui dentro do congá. Enquanto eu estiver orientando vocês durante a gira, o pessoal da equipe espiritual vai [estar] incorporando até pra que eu possa manipular não somente o axé dos Orixás, que está contido na casa, mas a energia que sairá das entidades manifestadas pra chegar até você, pra ativar o axé dentro de você. (LIVE..., 2020a, 2min51s).

Também, em outra gira, Kaim afirmou: “[...a] hora que eu estiver encaminhando a bênção, invocando a bênção dos Orixás e guias pra você, você sinta, feche teus olhos e deixe ser tomado por esse axé." (LIVE..., 2020b, 036s). Percebe-se, então, através das consideraçóes dos youtubers, o caráter paliativo no uso do recurso de streaming para a execução da prática religiosa emulada no espaço virtual.

\section{Discussáo, consideraçóes e desdobramentos}

A partir da problemática exposta neste artigo - um momento de crise no qual o ser religioso necessita praticar sua crença sob a adversidade, mesmo que isso implique fragmentaçóes identitárias - observa-se a desterritorialização parcial do espaço sagrado, uma vez que parte da egrégora não está presente fisicamente no terreiro, e sim, virtualmente, como espectadores em redes sociais, abstendo-se da hierofania presencial e participando da liturgia emulada em streaming. Diante desse cenário, considera-se que a ausência do corpo no espaço sagrado, tida, no caso da Umbanda, como essencial para a hierofania, reconfigura vários aspectos litúrgicos.

O primeiro deles é a incorporaçáo enquanto processo comunicacional entre o mundo espiritual e o mundo terreno: a incorporação, para os médiuns desterritorializados, não é uma prática recomendada, apesar de não ser proibida (vide os comentários citados anteriormente). A incorporação é entendida como indissociável do espaço sagrado, onde há a orientação do dirigente (pai ou mãe de santo) e a segurança energética do terreiro, com suas firmezas, assentamentos etc.

O segundo aspecto de reconfiguração diz respeito à ruptura causada na tríade entidade/ médium/consulente - elementos $(\mathrm{A})+(\mathrm{B})+(\mathrm{C})$-, desdobramento do fundamento umbandista "manifestação do espírito para a caridade". Essa ruptura tanto é causada pela ausência de incorporação do umbandista, que está dentro do espaço sagrado, transmitindo a gira na 
plataforma on-line (caso do youtuber Adérito Simóes, que não incorporou nas giras observadas no estudo), quanto pelo umbandista desterritorializado. Mesmo que a incorporação ocorra (caso do youtuber Márcio Kaim), ainda assim a liturgia não está completa, pela ausência do elemento $(\mathrm{C})$ - o consulente, significando a ausência da assistência individualizada presencial "um para um".

Percebe-se que as reconfiguraçóes expostas acima merecem aprofundamento e reflexão tanto no campo das Ciências Sociais, como na Comunicaçáo (enquanto processo comunicacional), quanto nas Ciências da Religião (enquanto alteraçôes em fundamentos religiosos). O recorte observado e analisado abrange um período de exceção, mas pode vir a ser uma tendência para um processo mediatizado duradouro e que alcance públicos que, devido à ausência de terreiros "físicos", lancem mão dessa alternativa para a prática religiosa.

Como desdobramentos possíveis, pode-se apontar algumas trilhas: em primeiro lugar, as giras online como espaço de resistência identitária, ou mesmo sobrevivência da prática religiosa, frente à pandemia, não sendo ela fruto de um determinismo tecnológico. Ao contrário: a utilização das mídias possibilita uma forma de expressão religiosa, de existência, mesmo que fragmentada. Em segundo lugar, para uma pesquisa de campo, sugere-se atenção ao potencial corpus que os pais e mães de santo youtubers possam fornecer em entrevistas (os objetos de estudo vão além dos utilizados neste artigo), bem como uma análise apurada de comentários nos vídeos, indicando possibilidades que referendem ou refutem o formato da gira on-line.

\section{Referências}

AZEVEDO, J. Tudo o que você precisa saber sobre Umbanda. São Paulo: Universo dos Livros, 2008.

BARBOSA JÚNIOR, A. O livro essencial de Umbanda. São Paulo: Universo dos Livros, 2014.

DRAVET, F. O imaginário ou a comunicação entre o corpo e linguagem: problematização do fenômeno da incorporação no Brasil. Conexáo - Comunicaçáo e Cultura, Caxias do Sul, v. 15, n. 30, p. 287-306, jul./dez. 2016.

ELIADE, M. O sagrado e o profano: a essência das religiōes. São Paulo: WMF Martins Fontes, 2019.

ESPÍRITOS diversos. Código de Umbanda. [Psicografado por Rubens Saraceni]. São Paulo: Madras, 2004.

GIRA on-line. [S. l.: s. n.], 2020a. 1 vídeo (46 min.). Publicado pelo canal Adérito Simóes. Disponível em: https://www.youtube.com/watch?v=yn4pJf6Y310\&list=PLjrLGdkeT6LcJFEbbB335UIKNI

CqdW4FD\&index=10\&t=221s. Acesso em: 15 jun. 2020.

:09/04/2020. [S. l.:s.n.], 2020b. 1 vídeo (1h29min.). Publicado pelo canal Adérito Simôes.

Disponível em: https://www.youtube.com/watch?v=Z8k0EP2eglU\&list=PLjrLGdkeT6Lc]FE 
bbB335UIKNJCqdW4FD\&index=13\&t=95s . Acesso em: 11 maio 2021.

HJARVARD, S. A midiatizaçáo da cultura e da sociedade. Sáo Leopoldo: Ed. Unisinos, 2014.

JURUÁ, P. Coletânea Umbanda "a manifestaçáo do espírito para a caridade": as origens da Umbanda I. São Caetano do Sul: [s. n.], 2013.

LÉVY, P. O que é o virtual? São Paulo: Ed. 34, 2011.

LIVE gira no TRUFRA. [S.l: s.n.], 2020a. 1 vídeo (1h40min). Publicado pelo canal Umband'Boa. Disponível em: https://www.youtube.com/watch?v=V3GsFpilnFo\&t=2815s. Acesso em: 10 jun. 2020.

MARQUIONI, C. A. Sobre preparação cultural, atenção e distração nos modos de assistir TV: uma análise do caso da experiência de múltiplas telas. Conexáo - comunicaçáo e cultura, UCS, Caxias do Sul, v. 17, n. 33, p. 39-59, jan./jun. 2018.

MARTINO, L. M. S. Mídia, religiáo e sociedade: das palavras às redes digitais. São Paulo: Paulus, 2016.

MIKLOS, J. A construção de vínculos religiosos na cibercultura: a ciber-religiấo. Tese (Doutorado em Comunicação e Semiótica) - Pontifícia Universidade Católica de São Paulo, 2010 .

MILLER, D.; SLATER, D. The internet: an ethnographic approach. Oxford: New York: Berg, 2000.

OMOLUBÁ. Doutrina e práticas umbandistas: cadernos de Umbanda. São Paulo: Ícone, 2014.

PIZA, V. T.; SILVA, M. R. Midiatização e religiōes mediúnicas: análise da produção audiovisual de um youtuber umbandista. Pensacom Brasil, São Paulo, Sociedade Brasileira de Estudos Interdisciplinares da Comunicação; Serviço Social do Comércio - SESC São Paulo, 9 e 10 dez. 2019.

REIS, S. M. dos. Universo umbandista: Umbanda tem fundamento, é preciso preparar. [Livro eletrônico]. São Paulo: [s. n.], 2011.

RUSSEL, Bertrand. História da filosofia ocidental, livro 1: a filosofia antiga. Rio de Janeiro: Nova Fronteira, 2015.

SODRÉ, M. As estratégias sensíveis: afeto, mídia e política. Petrópolis: Vozes, 2006.

SOUZA, M. T. Midia e religiáo: dispositivos em conexão: a reconfiguraçáo da experiência religiosa no mundo digital. In: GOMES, P. G. [et. al.]. Mídias e religióes: a comunicação e a fé em sociedades em midiatização. São Leopoldo: Ed. Unisinos, 2013. 1 CD-ROM.

SPADARO, A. O mistério da Igreja na era das mídias digitais. In: GOMES, P. G. [et. al.]. Mídias e religióes: a comunicação e a fé em sociedades em midiatização. São Leopoldo: Ed. Unisinos, 2013. 1 CD-ROM.

TEIXEIRA FILHO, C.; AZEVEDO JÚNIOR, A. C. Umbanda midiatizada: entre consumo, 
músicas e experiências pessoais. In: CAMARGO, H. W. (Org.). Umbanda, cultura e comunicação: olhares e encruzilhadas. Curitiba: Syntagma Editores,2019.

WILLIAMS, R. Televisáo: tecnologia e forma cultural. São Paulo: Boitempo; Belo Horizonte: PUC Minas, 2016. 